\title{
Soyasaponins reduce inflammation by downregulating MyD88 expression and suppressing the recruitments of TLR4 and MyD88 into lipid rafts
}

Junbin Chen ${ }^{1 \dagger}$, Hidayat Ullah ${ }^{1+}$, Zhongdaixi Zheng ${ }^{1 \dagger}$, Xiangfu Gu', Chuhong Su', Lingyu Xiao ${ }^{1}$, Xinglong Wu', Fei Xiong ${ }^{1}$, Qing $\mathrm{Li}^{2^{*}}$ and Longying Zha ${ }^{{ }^{*}}$ (D)

\begin{abstract}
Background: Previous studies indicate that soyasaponins may reduce inflammation via modulating toll-like receptor 4 (TLR4)/myeloid differentiation factor 88 (MyD88) signaling. However, its underlying mechanisms are still not fully understood.

Methods: Lipopolysaccharide (LPS)-challenged inflamed male ICR mice were intervened by intragastrical administration with 10 and $20 \mu \mathrm{mol} / \mathrm{kg} \cdot \mathrm{BW}$ of soyasaponin $\mathrm{A}_{1}, \mathrm{~A}_{2}$ or I for 8 weeks. The serum inflammatory markers were determined by commercial kits and the expression of molecules in TLR4/MyD88 signaling pathway in liver by real-time PCR and western blotting. The recruitments of TLR4 and MyD88 into lipid rafts of live tissue lysates were detected by sucrose gradient ultracentrifugation and western blotting. LPS-stimulated RAW264.7 macrophages were treated with 10, 20 and $40 \mu \mathrm{mol} / \mathrm{L}$ of soyasaponin $A_{1}, A_{2}$ or I for $2 \mathrm{~h}$. MyD88-overexpressed HEK293T cells were treated with 20 and $40 \mu \mathrm{mol} / \mathrm{L}$ of soyasaponins $\left(A_{1}, A_{2}\right.$ or I) or $20 \mu \mathrm{mol} / \mathrm{L}$ of ST2825 (a MyD88 inhibitor) for $6 \mathrm{~h}$. The expression of molecules in TLR4/MyD88 signaling pathway were determined by western blotting. Data were analyzed by using one way analysis of variance or t-test by SPSS 20.0 statistical software.

(Continued on next page)
\end{abstract}

\footnotetext{
* Correspondence: 1620351982@qq.com; lyzha@smu.edu.cn

†Junbin Chen, Hidayat Ullah and Zhongdaixi Zheng contributed equally to this work.

${ }^{2}$ Department of Dietetics, Nanfang Hospital, Southern Medical University, No.1838, Guangzhou 510515, Guangdong, People's Republic of China 'Department of Nutrition and Food Hygiene, Guangdong Provincial Key Laboratory of Tropical Disease Research, School of Public Health, Southern Medical University, No.1838 Guangzhou Avenue North, Guangzhou 510515, People's Republic of China
}

C C The Author(s). 2020 Open Access This article is licensed under a Creative Commons Attribution 4.0 International License, which permits use, sharing, adaptation, distribution and reproduction in any medium or format, as long as you give appropriate credit to the original author(s) and the source, provide a link to the Creative Commons licence, and indicate if changes were made. The images or other third party material in this article are included in the article's Creative Commons licence, unless indicated otherwise in a credit line to the material. If material is not included in the article's Creative Commons licence and your intended use is not permitted by statutory regulation or exceeds the permitted use, you will need to obtain permission directly from the copyright holder. To view a copy of this licence, visit http://creativecommons.org/licenses/by/4.0/. The Creative Commons Public Domain Dedication waiver (http://creativecommons.org/publicdomain/zero/1.0/) applies to the data made available in this article, unless otherwise stated in a credit line to the data. 
(Continued from previous page)

Results: Soyasaponins $A_{1}, A_{2}$ or I significantly reduced the levels of tumor necrosis factor alpha (TNFa), interleukin (IL)-6 and nitric oxide (NO) in serum ( $p<0.05)$, and decreased the mRNA levels of TNFa, IL-6, IL-1 $\beta$, cyclooxygenase 2 (COX-2) and inducible nitric oxide synthase (iNOS) $(p<0.05)$, the protein levels of myeloid differentiation protein 2 (MD-2), TLR4, MyD88, toll-interleukin1 receptor domain containing adaptor protein (TIRAP), phosphorylated interleukin-1 receptor-associated kinase 4 (p-IRAK-4), phosphorylated interleukin-1 receptor-associated kinase 1 ( $p$ IRAK-1) and TNF receptor associated factor 6 (TRAF6) $(p<0.05)$, and the recruitments of TLR4 and MyD88 into lipid rafts in liver $(p<0.05)$. In LPS-stimulated macrophages, soyasaponins $A_{2}$ or I significantly decreased MyD88 ( $p<$ 0.05), soyasaponins $A_{1}, A_{2}$ or I reduced p-IRAK-4 and p-IRAK-1 $(p<0.05)$, and soyasaponin I decreased TRAF6 ( $p<$ 0.05). In MyD88-overexpressed HEK293T cells, soyasaponins ( $A_{1}, A_{2}$ or I) and ST2825 significantly decreased MyD88 and TRAF6 $(p<0.05)$.

Conclusion: Soyasaponins can reduce inflammation by downregulating MyD88 expression and suppressing the recruitments of TLR4 and MyD88 into lipid rafts. This study provides novel understanding about the antiinflammatory mechanism of soyasaponins.

Keywords: Soyasaponin, Toll-like receptor 4 (TLR4), Myeloid differentiation factor 88 (MyD88), Inflammation, Lipid raft

\section{Background}

Non-communicable chronic diseases (NCDs), such as cardiovascular diseases, diabetes, cancer, etc. are increasingly prevalent and have become the leading causes of mortality worldwide according to the World Health Organization (WHO) reports [1]. Although the pathogenesis of NCDs is diversified, inflammation (especially chronic inflammation) is the common one and plays very important roles in the occurrence and development of NCDs [2]. Reduction of inflammation by pharmaceutical and/or nutritional methods is effective in the prevention and treatment of NCDs [3]. However, controlling inflammation by pharmaceutical methods usually brings adverse effects [4]. In the past several decades, the plant food-borne secondary metabolites (phytochemicals) have attracted intensive research interests because they possess a wide-range of health-promoting bioactivities including anti-inflammation and exhibit great potentials in the prevention of NCDs $[5,6]$. Soyasaponins are a group of phytochemicals that are present in soybeans and its products with an average content in soybeans varying from 0.17 to $6.16 \%$ [7]. They are oleanane triterpenoid glycosides constructing with a non-polar pentacyclic ring and polar sugar chains, and generally classified into four main groups (A, B, E and DDMP) according to the chemical structure of soyasapogenol [8]. The group A soyasaponins including sixteen members $\left(A_{1}, A_{2}, A_{3}, A_{4}, A_{5}, A_{6}, A a\right.$ or acetyl $A_{4}, A b$ or acetyl $A_{1}, A c, A d, A e$ or acetyl $A_{5}$, Af or acetyl $A_{2}$, Ag or acetyl $A_{6}$, Ah or acetyl $A_{3}, A_{X}$ and $A_{3}$ ) and group $B$ soyasaponins containing seven main members $\left(\mathrm{B}_{\mathrm{a}}\right.$ or $\mathrm{V}, \mathrm{B}_{\mathrm{b}}$ or $\mathrm{I}, \mathrm{B}_{\mathrm{c}}$ or II, $\mathrm{B}_{\mathrm{b}}$ ' or III, $\mathrm{B}_{\mathrm{c}}{ }^{\prime}$ or $\mathrm{B}_{\mathrm{X}}$, IV and $\mathrm{B}_{\mathrm{h}}$ ) are naturally the most abundant types in soybean and its related products $[8,9]$. Soyasaponins have multiple healthpromoting effects such as anticarcinogenic, hypocholesterolemic, hepatoprotective, immunomodulatory, neuroprotective, anticoagulant, and antioxidant bioactivities [7-9].
In recent years, the anti-inflammatory bioactivities of soyasaponins have attracted considerable research interests. Kang et al. (2005) found that total crude soyasaponin extracts containing soyasaponin I and soyasaponin II as major saponins ( $>50 \%$ of total saponins) inhibited the release of prostaglandin $\mathrm{E}_{2}\left(\mathrm{PGE}_{2}\right)$, nitric oxide $(\mathrm{NO})$, tumor necrosis factor alpha (TNF $\alpha)$ and monocyte chemoattractant protein (MCP)-1 in a dose-dependent manner and down-regulated the mRNA/protein expression levels of cyclooxygenase (COX)-2 and inducible nitric oxide synthase (iNOS) by blocking IkB-a degradation in lipopolysaccharide (LPS)-stimulated peritoneal macrophages [10]. Our previous studies showed that three purified soyasaponin monomers $\left(A_{1}, A_{2}\right.$, or $\left.I\right)$ could inhibit the production of $\mathrm{NO}$ and TNFa, the iNOS enzyme activity, and the iNOS mRNA expression in a dose-dependent manner through attenuation of NF- $\mathrm{kB}$ activation in LPSstimulated RAW264.7 macrophages [11]. Lee et al. (2010) also found that soyasaponin I inhibited the production of inflammatory cytokines (TNFa and IL- $\beta$ ), inflammatory mediators ( $\mathrm{NO}$ and $\mathrm{PGE}_{2}$ ), and inflammatory enzymes (COX-2 and iNOS) by suppressing the phosphorylation of I $\mathrm{B}-\mathrm{a}$ and the nuclear translocation of NF-kB in LPSstimulated macrophages. Moreover, soyasaponin I could significantly reduce inflammatory markers, proinflammatory cytokines and NF- $\mathrm{kB}$ activation in the colon in 3, 4, 5-trinitrobenzenosulfonic acid (TNBS)-induced colitic mice [12]. Soyasaponin $A_{b}$ not only inhibited NO, $\mathrm{PEG}_{2}, \mathrm{TNFa}$ and IL-1 $\beta$ in LPS-stimulated peritoneal macrophages but also suppressed the expression of COX-2 and iNOS, and activation of NF- $\mathrm{kB}$ in TNBS-induced colitic mice. Furthermore, soyasaponin $A_{b}$ weakly inhibited the phosphorylation of ERK, JNK and p38 in LPSstimulated peritoneal macrophages [13]. Soyasaponin $\mathrm{A}_{3}$ and two types of soyasapogenols (B and $\mathrm{C}$ ) also exhibited 
anti-inflammatory activities by inhibiting TNFa-induced expression of intercellular adhesion molecule-1 (ICAM-1) in THP-1 human monocytic leukemia cells [14]. Kinjo et al. (2000) reported that soyasaponin III had antiinflammatory properties by exhibiting in vitro anticomplementary activity [15]. More recently, Lan et al. isolated and identified five new triterpenoid saponins from green vegetable soya beans and found that three of them exhibited moderate anti-inflammatory activities by inhibiting the release of NO in LPS-stimulated RAW264.7 cells [16]. We recently found that soyasaponins $\left(\mathrm{A}_{1}, \mathrm{~A}_{2}\right.$ or $\left.\mathrm{I}\right)$ inhibited inflammation (reduced $\mathrm{PGE}_{2}$ production and COX-2 expression) by suppressing the reactive oxygen species (ROS)-mediated activation of the phosphoinositide 3-kinase (PI3K)/protein kinase $\mathrm{B}$ (Akt)/ NF- $\mathrm{kB}$ signaling pathway [17]. Moreover, soyasaponins $\left(A_{1}, A_{2}\right.$ or I) could reduce inflammation in both liver and white adipose tissue in high fat diet (HFD)-induced obese male C57BL/6 J mice [7]. These studies provide evidences that soyasaponins have anti-inflammatory bioactivities both in vivo and in vitro. Collectively, the molecular mechanisms underlying soyasaponin's anti-inflammatory bioactivities are associated with the inhibitory modulation on signaling pathway including nuclear factor kappa B (NF-кB) $[7,11$, 12, 17], phosphoinositide 3-kinase/protein kinase B (PI3K/ Akt) $[7,17]$ and mitogen activated protein kinases (MAPKs) $[13,18,19]$. The NF-kB and MAPKs signaling pathways are known to be the downstream targets of Toll-like receptor (TLR) signaling pathway including TLR4 [20], which suggests the possible involvement of TLR4 in soyasaponin's anti-inflammatory mechanism.

TLR4 signaling pathway is a part of innate immunity and one of the most important TLRs in the regulation of inflammation [21]. TLR4 mainly localizes on the cell surface of macrophages and other innate immune cells. It recognizes pathogen-associated molecular patterns (PAMPs) like LPS from Gram-negative bacteria, fusion (F) protein from respiratory syncytial virus, etc. and endogenous ligands including heat-shock proteins, hyaluronic acid, $\beta$-defensin 2 and palmitic acid [20, 22]. LPS is one of the best studied immunostimulatory exogenous ligands for TLR4 and can induce both systemic and local tissue inflammation [20]. LPS first combines with the LPS-binding protein (LBP) and then forms a signaling complex with TLR4, myeloid differentiation protein-2 (MD-2), and cluster of differentiation 14 (CD14) to initiate the intracellular signal transduction. The TLR4 intracellular signaling is divided into myeloid differentiation factor 88 (MyD88)-dependent and toll/interleukin 1 receptor domain-containing adaptor inducing IFN- $\beta$ (TRIF)-dependent (MyD88-independent) pathways [23]. It has been shown that MyD88-dependent pathway is responsible for the expression of pro-inflammatory cytokines, while the MyD88-independent pathway mediates the induction of type 1 interferon-inducible genes [20]. Upon LPS stimulation, MyD88 recruits and activates IL1 receptor-associated kinase-4 (IRAK-4) which results in the subsequent recruitment, activation and degradation of IRAK-1 [24]. Then, the tumor necrosis factor (TNF) receptor-associated factor 6 (TRAF6) is activated downstream of IRAK4/IRAK1 by forming a complex with ubiquitin-conjugating enzyme 13 (Ubc13) and ubiquitinconjugating enzyme $E_{2}$ variant 1 isoform $A$ (Uev1A). This further activates transforming growth factor- $\beta$ activated kinase 1 (TAK1) [25]. TAK1 then activates both downstream IKB kinase (IKK) and mitogenactivated protein kinase (MAPK) pathway. The activated IKK $(a / \beta / \gamma)$ complex phosphorylates the inhibitor of NF$\kappa \mathrm{B}(\mathrm{I} \kappa \mathrm{B})$, leading to I $\kappa \mathrm{B}$ degradation and NF- $\kappa \mathrm{B}$ activation. NF- $\mathrm{KB}$ activation thus stimulates the expression of pro-inflammatory cytokines (IL-1 $\beta$, IL-6, IL-8 and TNFa) $[20,24,25]$. MAPK activation induces transcription factor AP-1 which also stimulates the expression of proinflammatory cytokines [26]. The TLR4/MyD88 signaling pathway has been shown to be the target of many phytochemicals with anti-inflammatory bioactivities [21].

Lee et al. (2011) found that soyasaponin Ab inhibited the expression of TLR4 and the phosphorylation of IRAK-1 in both the colon of TNBS-induced colitic mice and the LPS-stimulated peritoneal macrophages. Furthermore, soyasaponin Ab significantly inhibited the binding of LPS to TLR4 on macrophages [13]. Fussbroich et al. (2015) indicated that soyasaponin I not only inhibited TLR4- but also TLR2-induced inflammation, while it had no effect on the expression of TLR4 and TLR2 in LPS-stimulated MUTZ-3 cells [27]. We recently showed that soyasaponin $\mathrm{I}(\mathrm{Bb})$ inhibited the recruitment of TLR4, MyD88 and TRIF into lipid rafts in LPSstimulated RAW264.7 macrophages [18]. Additionally, soyasaponin $\mathrm{Bb}$ suppressed the LPS-induced formation of TLR4/MyD88 and TLR4/TRIF complexes in lipid rafts. However it did not affect the total expression levels of TLR4, MyD88 and TRIF [18]. These studies indicate that soyasaponins may modulate TLR4 signaling pathway in the situation of inflammation. However, the modulatory mechanisms of soyasaponins (especially different chemical structures of monomers) on TLR4 signaling pathway are still not fully understood. The objective of this study is to investigate the modulatory effects of three types of soyasaponin monomers $\left(\mathrm{A}_{1}, \mathrm{~A}_{2}\right.$ or $\left.\mathrm{I}\right)$ on TLR4 signaling both in vitro and in vivo.

\section{Methods}

\section{Reagents and chemicals}

Soyasaponin monomers $\left(A_{1}, A_{2}\right.$ or $\left.I\right)$ were prepared by using the methods as previously described [11]. Antibodies for MD-2 and TRAF6 were purchased from Abcam (Cambridge, MA, USA). Antibody for TLR4 (25) 
was from Santa Cruz Biotechnology, Inc. (Santa Cruz, CA, USA). LPS and antibodies for TIRAP and flotillin-1 were from Sigma (Saint Louis, MO, USA). Antibody for phospho-IRAK4 (p-IRAK4, Thr345) and phosphoIRAK1 (p-IRAK1, Ser376) were from Bioss (Beijing, China). Antibody for cluster of differentiation 68 (CD68) was purchased from Proteintech (Wuhan, Hubei, China). Antibody for GAPDH was from Good here (Hangzhou, Zhejiang, China). Antibodies for MyD88, $\beta$-actin and all secondary antibodies used for western blotting were from Cell Signaling Technology, Inc. (Danvers, MA, USA). TRIZOL reagent was purchased from Invitrogen (Invitrogen, USA).

\section{LPS-challenged inflammatory mice model}

A total of 135 9-weeks old male ICR (Institute of Cancer Research) mice were purchased from Guangdong Medical Lab Animal Center (Certification No. 44007200030072). All animals were housed in standard cages with five mice in each cage in an environment of $21-23^{\circ} \mathrm{C}$ and $50-60 \%$ humidity on a $12 \mathrm{~h} / 12 \mathrm{~h}$ light/dark cycle in the specific pathogen free (SPF) lab animal house. All mice were fed with standard AIN-93G chow diet and allowed ultrapure water ad libitum. The diet was free of soybean and its products in order to avoid containing soyasaponins or soyasapogenols. After 1 week of acclimatization, all mice were randomly allotted to the control group $(n=15)$ and the LPS group $(n=120)$. Mice in the LPS group were intravenously injected with LPS $(100 \mu \mathrm{g} / \mathrm{kg} \cdot \mathrm{BW})$ via tail vein once a week for a continuous 8 weeks. Meanwhile, mice in the control group were injected with normal saline (NS) in the same way. At the end of the 8-weeks LPS challenge, blood was collected via tail vein of mice and further prepared as serum. The inflammatory markers (TNF $\alpha$, IL-1 $\beta$, IL-6, $\mathrm{PGE}_{2}$ and NO) in serum were determined to investigate the inflammatory status of mice. The body weight and feed consumption were recorded weekly.

\section{Soyasaponins intervention on LPS-challenged inflamed mice}

Following LPS challenge for 8 weeks, the intervention trial was then carried out. The mice $(n=15)$ in the control group were still used as a negative control and designated to group 1 (G1), and were intragastrically administered with NS containing $0.5 \%$ ethanol (ethanol is the solvent for soyasaponins). All mice $(n=120)$ in the LPS group were randomly divided into eight groups (G2 to G9) with 15 mice in each group $(n=15)$. Mice in G2 were intragastrically administered with NS containing $0.5 \%$ ethanol as a positive control. Mice in G3 were intragastrically administrated with $0.1 \mathrm{mg} / \mathrm{kg} \cdot \mathrm{BW}$ of aspirin. Mice in G4 and G5 were intragastrically administrated with 10 and $20 \mu \mathrm{mol} / \mathrm{kg} \cdot \mathrm{BW}$ of soyasaponin $\mathrm{A}_{1}$, respectively. Mice in G6 and G7 were intragastrically administrated with 10 and $20 \mu \mathrm{mol} / \mathrm{kg} \cdot \mathrm{BW}$ of soyasapo$\operatorname{nin} \mathrm{A}_{2}$, respectively. Mice in G8 and G9 were intragastrically administrated with 10 and $20 \mu \mathrm{mol} / \mathrm{kg} \cdot \mathrm{BW}$ of soyasaponin I, respectively. Both aspirin and soyasaponins were dissolved in NS containing $0.5 \%$ ethanol. All gavage were administrated once a day (in the afternoon in the animal house) for a total intervention period of 8 weeks. During the intervention trial, the diets and ultrapure water were also provided ad libitum. The body weight and feed consumption were recorded weekly.

After an 8-h overnight fast at the end of intervention trial, mice were weighed and sedated with pentobarbital ( $50 \mathrm{mg} / \mathrm{kg}$ body weight) by peritoneal injection and sacrificed by cervical dislocation. The serum and tissue samples were immediately collected and stored at $80^{\circ} \mathrm{C}$ for further analysis.

\section{Analysis of inflammatory markers in serum}

The inflammatory markers including pro-inflammatory cytokines (TNF $\alpha$, IL-1 $\beta$ and IL-6) and inflammatory mediators $\left(\mathrm{PGE}_{2}\right.$ and $\left.\mathrm{NO}\right)$ in serum were analyzed. TNF $\alpha$, IL-1 $\beta$, IL-6 and PGE $_{2}$ were detected by using ELISA assay with commercial kits (Genetimes ExCell Technology Company, Shanghai, China) following the manufacturer's instructions. NO was determined by the Griess reaction using a commercial kit purchased from Nanjing Jiancheng Bioengineering Institute (Nanjing, Jiangsu, China).

\section{Real-time fluorescent quantitative polymerase chain reaction (FQ-PCR)}

The mRNA expression of inflammatory markers (TNF $\alpha$, IL-1 $\beta$, IL-6, iNOS and COX-2) in liver tissues was detected by using FQ-PCR. Preparation of total RNA, cDNA synthesis, and PCR were operated as described previously [7]. The primers used were as follows: TNF $\alpha$ (forward: 5'-CCACCACGCTCTTCTGTCTA-3', reverse: $\quad$ 5'-TGGTTTGTGAGTGTGAGGGT-3'), IL-6 (forward: 5'-TTCTTGGGACTGATGCTGGT-3', reverse: 5 '-CAGGTCTGTTGGGAGTGGTA -3'), IL-1 $\beta$ (forward: 5'-TGACGGACCCCAAAAGATGA-3', reverse: 5'-CTGCTGCGAGATTTGAAGCT-3'), iNOS (forward: 5'-ACCCAAGGTCTACGTTCAGG-3', reverse: 5'-CGCACATCTCCGCAAATGTA-3'), COX-2 (forward: 5'-CAGGTCATTGGTGGAGAGGT-3', reverse: $5^{\prime}$-TCAGGGATGTGAGGAGGGTA-3'), $\beta$-actin (forward: 5'-GTGGGAATGGGTCAGAAGGA-3', reverse: 5 '-CTTCTCCATGTCGTCCCAGT-3'). Samples were normalized by dividing the quantity of the indicated molecules' genes by the value of a house-keeping gene $(\beta$-actin) in the same sample. Results were presented as mRNA relative expression (folds to the control, which denoted as 1). 


\section{Lipid rafts isolation by sucrose gradient} ultracentrifugation

Liver tissues were suspended in $2.1 \mathrm{~mL}$ ice-cold MBS buffer [25 mM 2-(N-morpholino)-ethanesulfonic acid (MES, pH 6.5) and $0.15 \mathrm{M} \mathrm{NaCl}$ ] containing $1 \%$ Triton $\mathrm{X}-100,1 \mathrm{mM}$ phenylmethylsulfonyl fluoride (PMSF) and $1 \%$ protease inhibitor cocktail (Sigma), lysed by homogenization, and then incubated on ice for $30 \mathrm{~min}$ followed by centrifugation at $700 \mathrm{rpm}, 4{ }^{\circ} \mathrm{C}$ for $10 \mathrm{~min}$. The supernatants $(2.1 \mathrm{~mL})$ were mixed with $2.1 \mathrm{~mL} 80 \%$ sucrose solution in MBS buffer and then transferred to the bottom of centrifuge tubes. These samples were overlaid with $4.2 \mathrm{~mL}$ of $30 \%$ sucrose in MBS buffer, followed by $2.1 \mathrm{~mL}$ of $5 \%$ sucrose in MBS buffer. After the samples were centrifuged at $39,000 \mathrm{rpm}$ for $20 \mathrm{~h}$ at $4{ }^{\circ} \mathrm{C}$ in a Hitachi P40ST rotor, twelve $0.875 \mathrm{~mL}$ fractions were collected from the top of the gradient and transferred into separated tubes. Fractions were precipitated by using trichloroacetic acid method.

\section{Cell culture}

RAW264.7 murine macrophages (ATCC ${ }^{\circ}$ TIB-71 $^{\mathrm{mm}}$ ) and HEK293T cells $\left(\right.$ ATCC $^{\circ}$ CRL-11268 ${ }^{\text {ru }}$ ) were maintained in DMEM (Gibco, Grand island, NY, USA) containing $10 \%(\mathrm{v} / \mathrm{v})$ fetal bovine serum (Clark, Richmond, VA, USA) and $1 \%(\mathrm{v} / \mathrm{v})$ penicillin-streptomycin in a humidified atmosphere containing $5 \% \mathrm{CO}_{2}$ at $37^{\circ} \mathrm{C}$.

In the LPS challenge experiments, RAW264.7 macrophages were stimulated with $1 \mu \mathrm{g} / \mathrm{mL}$ of LPS for different time $(0 \mathrm{~min}, 10 \mathrm{~min}, 30 \mathrm{~min}, 1 \mathrm{~h}, 3 \mathrm{~h}, 6 \mathrm{~h}, 12 \mathrm{~h}$ and $24 \mathrm{~h})$. In the soyasaponins intervention experiments, RAW264.7 macrophages were pre-incubated with graded concentrations $(10,20$ and $40 \mu \mathrm{mol} / \mathrm{L})$ of soyasaponin $\left(A_{1}, A_{2}\right.$ or $\left.I\right)$ for $2 \mathrm{~h}$ and then stimulated with $1 \mu \mathrm{g} / \mathrm{mL}$ of LPS for suitable times as determined by previous results.

\section{Cell transfection}

HEK293T cells were transfected with MyD88 flag expression plasmid (Addgene plasmid \#13093) or the empty plasmid vector using the Lipofectamine 3000 reagent (Invitrogen) by following the recommended protocols. HEK293T cells were transfected for $24 \mathrm{~h}$ and then treated with graded concentrations $(20$ or $40 \mu \mathrm{mol} / \mathrm{L})$ of soyasaponin $\left(\mathrm{A}_{1}, \mathrm{~A}_{2}\right.$ or $\left.\mathrm{I}\right)$, or $20 \mu \mathrm{mol} / \mathrm{L}$ of ST2825 (a MyD88 dimerization inhibitor) for $6 \mathrm{~h}$.

\section{Western blotting}

Western blotting was performed as previously described [7]. Briefly, mice liver tissues or cells samples were homogenized in RIPA lysis buffer (KeyGEN Biotech) containing $1 \mathrm{mM}$ PMSF, $1 \%$ protease inhibitors and $0.8 \%$ phosphatase inhibitors. Cell lysates were centrifuged (12, $000 \mathrm{rpm})$ for $10 \mathrm{~min}$. The lysates $(20-40 \mu \mathrm{g} /$ lane $)$ were subjected to 10\% SDS-PAGE gels and electrotransferred to PVDF membranes (Millipore, Billerica, MA, USA). The presence of proteins was detected by immunoblotting with primary antibodies overnight at $4{ }^{\circ} \mathrm{C}$ and followed by HRP-conjugated secondary IgG antibody. Immunoreactive bands were developed by using enhanced chemiluminescence and visualized by using the Tanon-5200 imaging system (Shanghai, China).

\section{Statistical analysis}

Statistical analyses were performed using one way analysis of variance (one-way ANVOA) and LSD or Dunnett's T3 multiple comparison tests or t-test by SPSS (edition 20.0) statistical software (SPSS Inc., Chicago, IL, USA). Results are expressed as Means \pm SD. Significant values $(p<0.05)$ were marked with an asterisk (*) or an octothorpe (\#).

\section{Results}

Soyasaponins decrease LPS-induced inflammation in ICR mice

LPS has been shown to induce both systemic and local tissue inflammation in mice [28]. In this study, we challenged the ICR mice with intravenous injection of LPS $(100 \mu \mathrm{g} / \mathrm{kg} \cdot \mathrm{BW})$ via tail vein once a week for a continuous 8 weeks to establish a model for mimicking the chronic inflammatory status, and then intervened with soyasaponins. As shown in Table S1, chronic challenge of LPS on ICR mice for 8 weeks significantly increased the inflammatory markers (TNF $\alpha$, IL-6, $\mathrm{PGE}_{2}$ and NO) in serum indicating the production of an systemically inflammatory status $(p<0.05)$. Unexpectedly, the IL- $1 \beta$ could not be detected by commercial ELISA kit in this study. Meanwhile, chronic challenge of LPS did not affect the growth (Fig. S1, A) and food consumption (Fig. S1, B) of mice $(p>0.05)$.

Following LPS challenge for 8 weeks, inflamed mice were then intervened by soyasaponins or aspirin for 8 weeks. As shown in Fig. 1, mice in the LPS group had significantly higher levels of TNF $\alpha$, IL- 6 and NO in serum $(p<0.05)$. Both soyasaponins $\left(\mathrm{A}_{1}, \mathrm{~A}_{2}\right.$ or I) and aspirin reduced the inflammatory markers (TNF $\alpha$, IL-6 and NO) in serum $(p<0.05)$. However, the level of $\mathrm{PGE}_{2}$ in serum was not affected $(p>0.05)$. Furthermore, intervention with soyasaponins $\left(A_{1}, A_{2}\right.$ or $\left.I\right)$ or aspirin for 8 weeks did not change the growth (Fig. S1 C) and feed consumption (Fig. S1 D) of mice $(p>0.05)$.

We further investigated the mRNA expression of inflammatory markers in liver tissues of mice. As shown in Table S2, mice in the LPS group had significantly higher mRNA expression of inflammatory markers (TNF $\alpha$, IL6 , IL-1 $\beta$, COX-2 and iNOS) in liver of ICR mice $(p<$ $0.05)$. Intervention with soyasaponins $\left(A_{1}, A_{2}\right.$ or $\left.I\right)$ or aspirin for 8 weeks significantly reduced the LPS-increased 

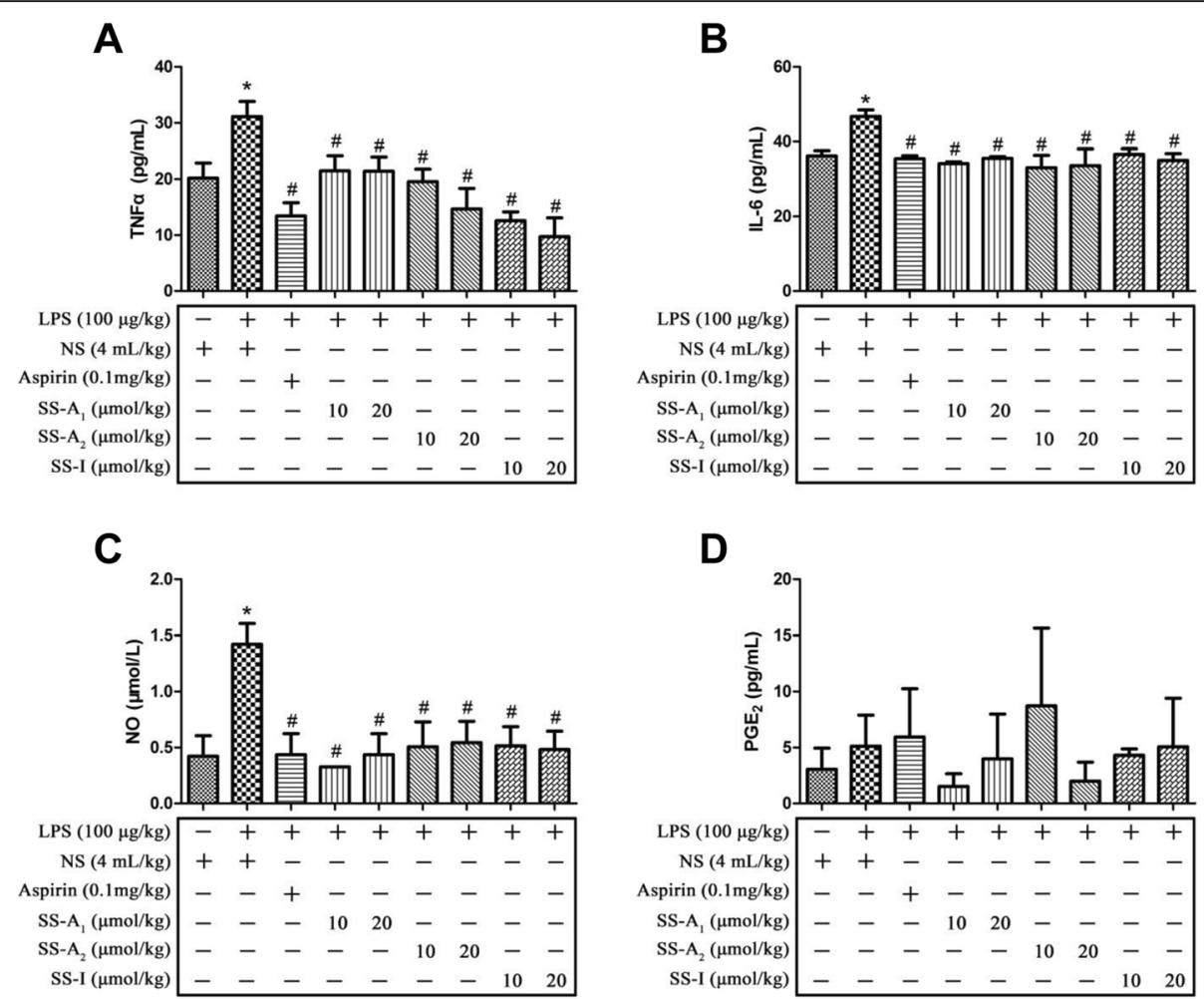

Fig. 1 Effects of soyasaponins on inflammatory markers in serum of LPS-challenged ICR mice. The serum levels of TNFa, IL-6, PGE 2 and NO were determined by commercial ELISA kits in LPS-induced inflammatory mice after intervention by aspirin or soyasaponins $\left(A_{1}, A_{2}\right.$ or I). Results reported are Means \pm SD of samples from 9 mice in each group $(n=9)$. Data were statistically analyzed by using one-way ANOVA of SPSS software. *: $p<0.05$ v.s. control, \#: $p<0.05$ v.s. LPS alone

mRNA expression of all these inflammatory markers $(p<0.05)$.

Together, these results indicate that long-term challenge with low-dosage of LPS can induce both systemic (in blood) and local (in liver tissues) inflammation in ICR mice and soyasaponins intervention can decrease the LPS-induced inflammation.

\section{Soyasaponins inhibit TLR4/MyD88 signaling in liver of LPS-challenged mice}

TLR4/MyD88 signaling plays primary role in LPS-induced inflammation and has been shown to be the target of many phytochemicals exhibiting anti-inflammatory bioactivities [28]. Here, we analyzed the TLR4/MyD88 signaling pathway in liver tissues of mice. As shown in Fig. 2, LPS challenge on mice activated TLR4/MyD88 signaling in liver as evidenced by increased expression of MD-2, TLR4, MyD88, TIRAP and TRAF6, and enhanced phosphorylation of IRAK- 4 and IRAK-1 $(p<0.05)$. Intervention of soyasaponins $\left(\mathrm{A}_{1}, \mathrm{~A}_{2}\right.$ or I) on LPS-challenged mice significantly decreased the expression of MD-2, TLR4, MyD88, TIRAP and TRAF6, and reduced the phosphorylation of IRAK-4 and IRAK-1 $(p<0.05)$ in liver tissues suggesting the inhibitory effects of soyasaponins on TLR4/
MyD88 signaling. Similarly, aspirin intervention on LPSchallenged mice also significantly decreased the expression of MD-2, TLR4, MyD88, TIRAP and TRAF6, and phosphorylation of IRAK-4 $(p<0.05)$ in liver. However, aspirin did not significantly affect the phosphorylation of IRAK-1 $(p>0.05)$. CD68 is specifically expressed in macrophages and used as a marker of macrophages' response to inflammation [22,29]. Here, LPS challenge significantly increased the CD68 expression in liver tissues indicating the macrophage-associated activation of inflammation there. Both soyasaponins $\left(A_{1}, A_{2}\right.$ or $\left.I\right)$ and aspirin significantly decreased the expression of CD68 in liver as compared with the LPS alone group $(p<0.05)$. These results show that soysasaponins can inhibit the LPS-induced activation of TLR4/MyD88 signaling in mice liver.

\section{Soyasaponins inhibit LPS-induced recruitments of TLR4 and MyD88 into lipid rafts of liver tissue lysates}

Lipid rafts have been shown to be essential for the activation of TLR4/MyD88 signaling [30]. We previously found that soyasaponins could reduce inflammation by inhibiting the recruitments of TLR4 and MyD88 into lipid rafts in murine macrophages in vitro [18]. To further address the potential anti-inflammatory mechanism 


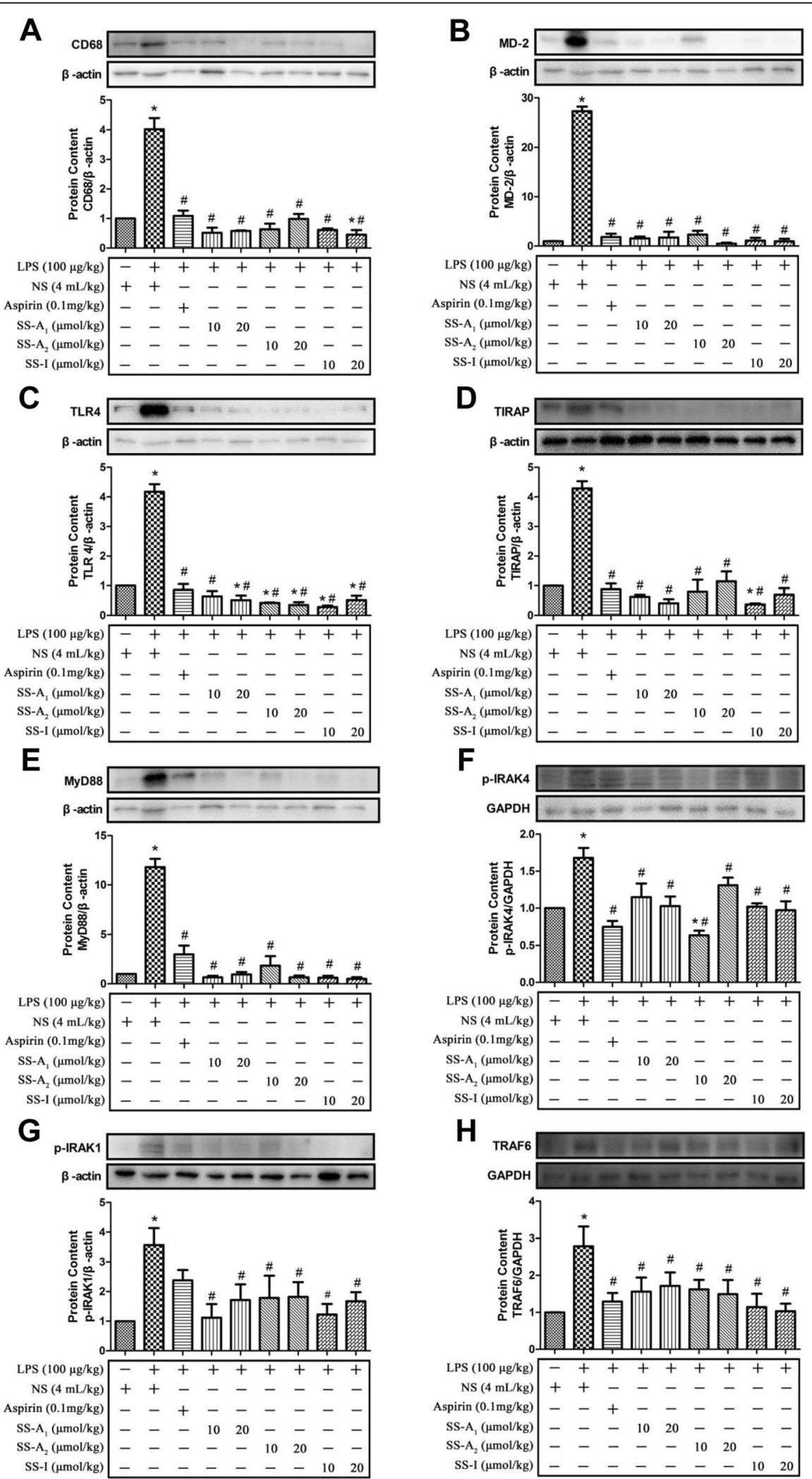

Fig. 2 (See legend on next page.) 
(See figure on previous page.)

Fig. 2 Soyasaponins reduced protein levels of molecules in TLR4/MyD88 signaling pathway and CD68 in the liver tissues of LPS-challenged mice. The protein levels of MD-2, TLR4, MyD88, TIRAP, p-IRAK4, p-IRAK1 and TRAF6 in TLR4/MyD88 signaling pathway, and CD68, a macrophage marker, were measured by western blotting. Results reported are Means \pm SD of samples from 6 mice in each group $(n=6)$. Data were statistically analyzed by using one-way ANOVA of SPSS software. *: $p<0.05$ v.S. control, \#: $p<0.05$ v.s. LPS alone

of soyasaponins in vivo, here we analyzed the recruitments of TLR4 and MyD88 into lipid rafts in liver tissues of LPS-challenged mice. As shown in Fig. 3a, flotillin-1, the marker of lipid rafts, was highly rich in fractions 3 and 4 of ultracentrifugation samples of liver tissues. As compared to the control, LPS challenge increased the recruitments of TLR4 and MyD88 into lipid rafts (mainly in fractions 3 and 4 ) of liver tissues (Fig. 3 a-c) $(p<0.05)$. Treatment of both soyasaponins $\left(\mathrm{A}_{1}, \mathrm{~A}_{2}\right.$ or I) and aspirin significantly reduced the LPS-increased levels of TLR4 and MyD88 in fractions 3 and 4 of liver tissues $(p<0.05)$ indicating the in vivo inhibitory bioactivities of soyasaponins on recruitments of these two molecules into lipid rafts (Fig. 3 a-c).

\section{Soyasaponins inhibit TLR4/MyD88 signaling in LPS- stimulated murine macrophages}

It is known that LPS-stimulated macrophages serve as a good in vitro cell model to investigate the TLR4/MyD88 signaling-mediated inflammation [20,31]. Here we used LPS-stimulated murine RAW264.7 macrophages to further understand the modulation of soyasaponins on TLR4/MyD88 signaling in vitro.

Firstly, we stimulated RAW264.7 macrophages with $1 \mu \mathrm{g} / \mathrm{mL}$ of LPS for different time $(0 \mathrm{~min}, 10 \mathrm{~min}, 30$ min, $1 \mathrm{~h}, 3 \mathrm{~h}, 6 \mathrm{~h}, 12 \mathrm{~h}$, and $24 \mathrm{~h}$ ) to understand the time-dependent change rule of protein levels of molecules in TLR4/MyD88 signaling pathway. As seen in Fig. S2, LPS stimulation for $10 \mathrm{~min}$ to $24 \mathrm{~h}$ did not produce significant change of the protein levels of MD-2, TLR4 and TIRAP in macrophages $(p>0.05)$ (Fig. S2 E). However, LPS treatment for $1 \mathrm{~h}$ or $3 \mathrm{~h}$ significantly increased the expression levels of MyD88 $(p<0.05)$ (Fig. S2 A). LPS stimulation for $3 \mathrm{~h}$ significantly increased the phosphorylation of IRAK4 $(p<0.05)$ (Fig. S2 B). LPS challenge for $3 \mathrm{~h}, 6 \mathrm{~h}$ or $12 \mathrm{~h}$ significantly increased the phosphorylation of IRAK1 $(p<0.05)$ (Fig. S2 C). Interestingly, LPS treatment for $30 \mathrm{~min}$ to $6 \mathrm{~h}$ significantly increased the levels of TRAF6 $(p<0.05)$, but LPS stimulation for $12 \mathrm{~h}$ or $24 \mathrm{~h}$ decreased the levels of TRAF6 $(p<0.05)$ (Fig. S2 D). These results indicated that LPS stimulation for as short as 30 min could activate TLR4/MyD88 signaling in murine macrophages. Therefore, $30 \mathrm{~min}$ was chosen as the starting time duration for LPS challenge in the next step experiment of soyasaponins intervention.

Secondly, we pre-incubated the murine macrophages with graded concentrations $(10,20$ or $40 \mu \mathrm{mol} / \mathrm{L})$ of soyasaponins $\left(\mathrm{A}_{1}, \mathrm{~A}_{2}\right.$, or I) for $2 \mathrm{~h}$, and then added $1 \mu \mathrm{g} /$ $\mathrm{mL}$ of LPS to stimulate the cells for $30 \mathrm{~min}, 1 \mathrm{~h}$ or $3 \mathrm{~h}$, and detected the protein expression levels of molecules in TLR4/MyD88 signaling pathway by western blotting. As shown in Fig. 4a, LPS stimulation on macrophages for $30 \mathrm{~min}$ did not change the protein levels of MD-2, TLR4, TIRAP, MyD88, p-IRAK4 and p-IRAK1. This is in agreement with the above results of time-dependent experiments. Soyasaponins pre-incubation produced no effect on the levels of MD-2, TLR4, TIRAP, MyD88, pIRAK4 and p-IRAK1 in LPS (for $30 \mathrm{~min}$ )-challenged macrophages. LPS stimulation for $30 \mathrm{~min}$ significantly increased the level of TRAF6, while this LPS-induced increase of TRAF6 was blunted by pre-treatment of soyasaponin I, but not by soyasaponins $\mathrm{A}_{1}$ and $\mathrm{A}_{2}$ (Fig. $4 \mathrm{~b}$ ). LPS stimulation for $1 \mathrm{~h}$ significantly increased the level of MyD88, which was blocked by pre-incubation of soyasaponin $A_{2}(40 \mu \mathrm{mol} / \mathrm{L})$ and soyasaponin I $(10 \mu \mathrm{mol} / \mathrm{L})$ (Fig. 4b). LPS stimulation for $3 \mathrm{~h}$ significantly increased the phosphorylation of IRAK4 (Fig. 4c) and IRAK1 (Fig. 4d) which was blocked by pre-incubation of all soyasaponins $\left(A_{1}, A_{2}\right.$ or $\left.I\right)$. These results show that soyasaponins can inhibit the TLR4/MyD88 signaling by downregulating the molecule expressions in LPSstimulated murine macrophages.

\section{Soyasaponins inhibit the expression of MyD88 and TRAF6 in MyD88-transfected HEK293T cells}

Based on the above results in LPS-stimulated murine macrophages, MyD88 was the first upstream molecule that was modulated by soyasaponins in TLR4/MyD88 signaling pathway suggesting MyD88 might be the key target of soyasaponins. Therefore, we applied MyD88 overexpression cell model to further understand the modulation of soyasaponins on TLR4/MyD88 signaling. Human embryonic kidney (HEK) $293 \mathrm{~T}$ cells normally express low levels of TLR4 and MyD88 [32]. As shown in Fig. 5, transfection of MyD88 plasmid in HEK293T resulted in high expression levels of MyD88, and also increased the expression of TRAF6, and activated the downstream NF- $\mathrm{kB}$ as evidenced by increased ratio of phosphorylated p65 (p-p65) to p65. However, MyD88 plasmid transfection did not affect the expression of upstream molecule of TLR4 in HEK293T cells $(p>0.05)$. Soyasaponins $\left(A_{1}, A_{2}\right.$, or $I$ ), similar to ST2825 (the MyD88 inhibitor), significantly decreased the MyD88 plasmid transfection-induced increase of MyD88 expression levels in HEK293T cells $(p<0.05)$. Furthermore, 


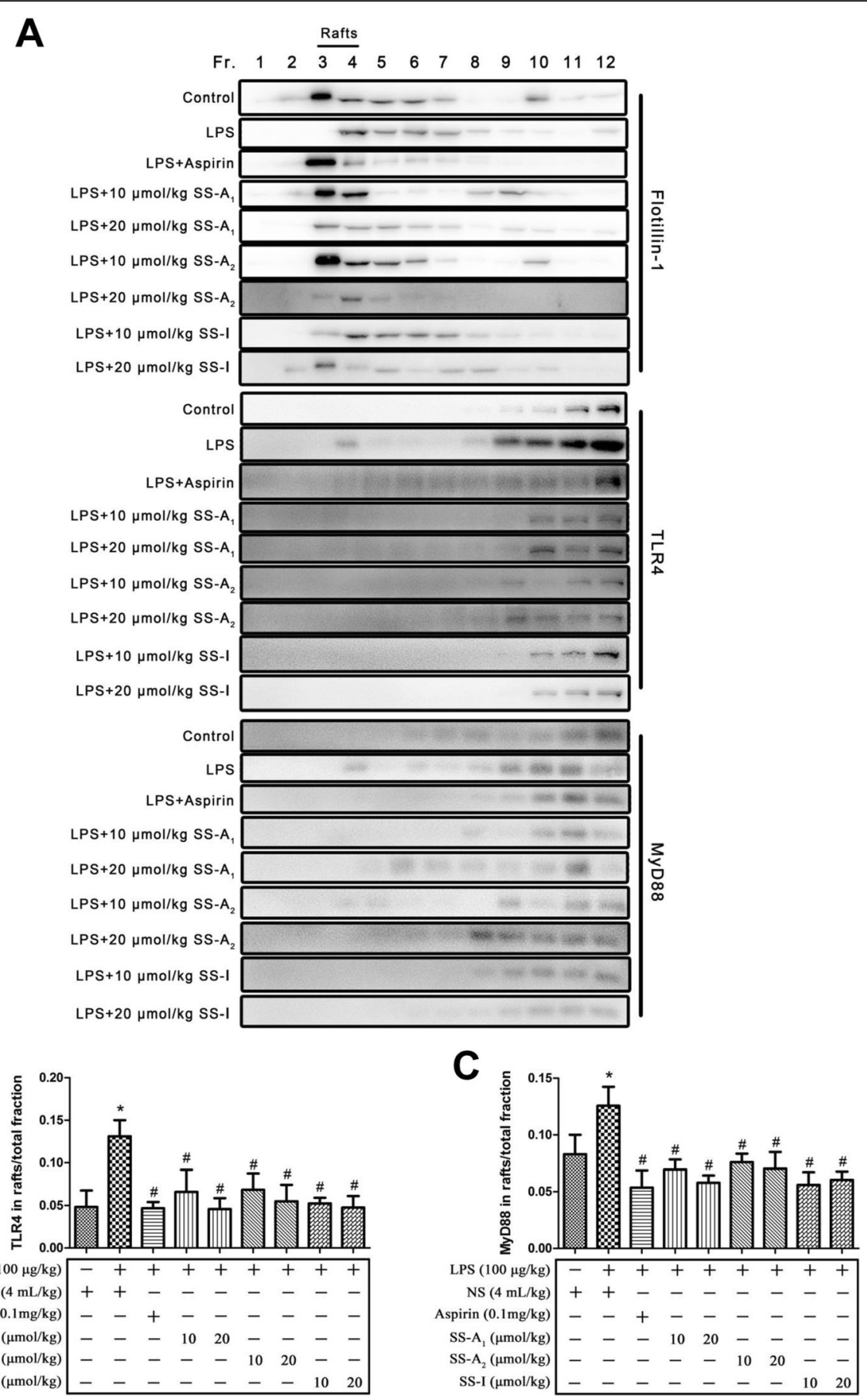

Fig. 3 Soyasaponins inhibited the recruitments of TLR4 and MyD88 into lipid rafts in liver tissues. The lipid rafts (fraction 3 and 4) were fractionated from liver tissue lysates by using sucrose gradient ultracentrifugation. The protein levels of flotillin-1 (a lipid raft marker), TLR4 and MyD88 were detected by western blotting. The ratio of the amount of TLR4 (or MyD88) in lipid raft to that in total fractions were quantitatively calculated. Results reported are Means \pm SD of samples from six mice in each group $(n=6)$. Data were statistically analyzed by using one-way ANOVA of SPSS software. * $p<0.05$ V.S. control, \#: $p<0.05$ v.S. LPS alone

soyasaponin $A_{1}(20 \mu \mathrm{mol} / \mathrm{L}), \mathrm{A}_{2}(40 \mu \mathrm{mol} / \mathrm{L})$, I (both 20 and $40 \mu \mathrm{mol} / \mathrm{L}$ ) and ST2825 significantly decreased the TRAF6 levels $(p<0.05)$. Meanwhile, soyasaponin $\mathrm{A}_{1}$ $(20 \mu \mathrm{mol} / \mathrm{L})$ and ST2825 significantly reduced the activation of NF- $\mathrm{kB}$ (decreased the ratio of p-p65 to p65) $(p<0.05)$. Neither soyasaponins $\left(\mathrm{A}_{1}, \mathrm{~A}_{2}\right.$, or I) nor ST2825 affected the TLR4 level in MyD88 plasmidtransfected HEK293T cells $(p>0.05)$. Together, these 


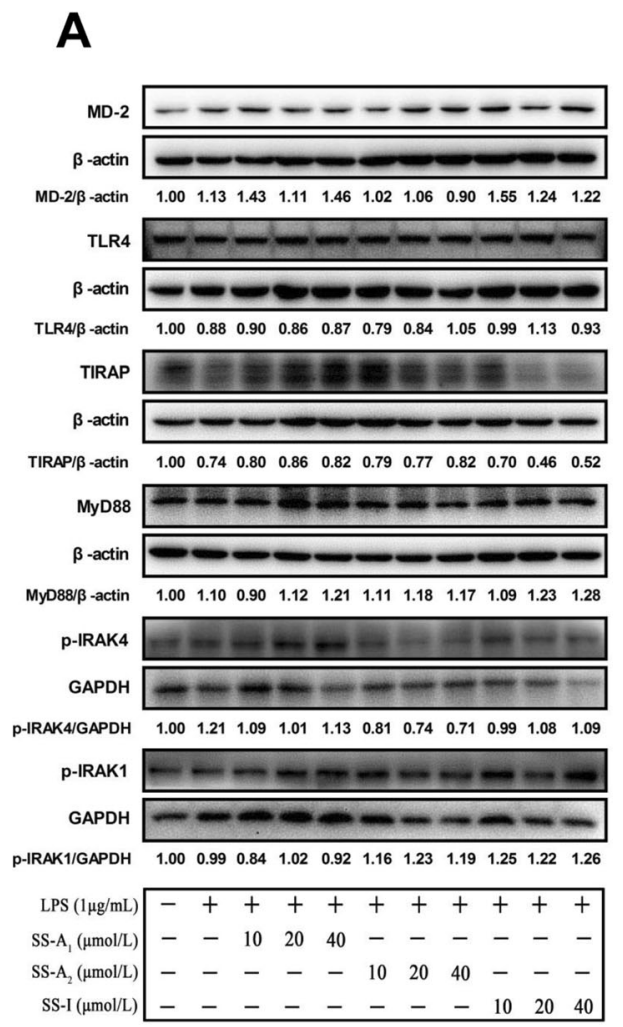

D

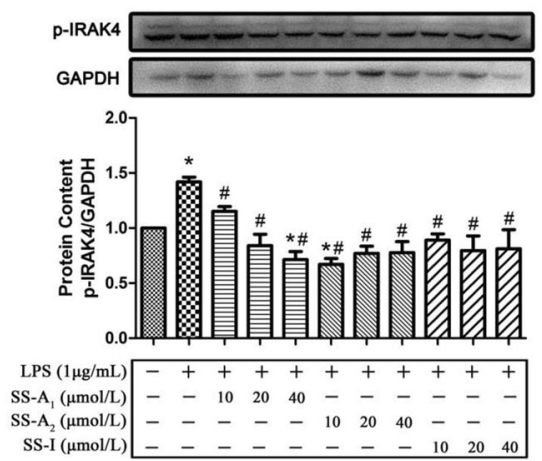

B

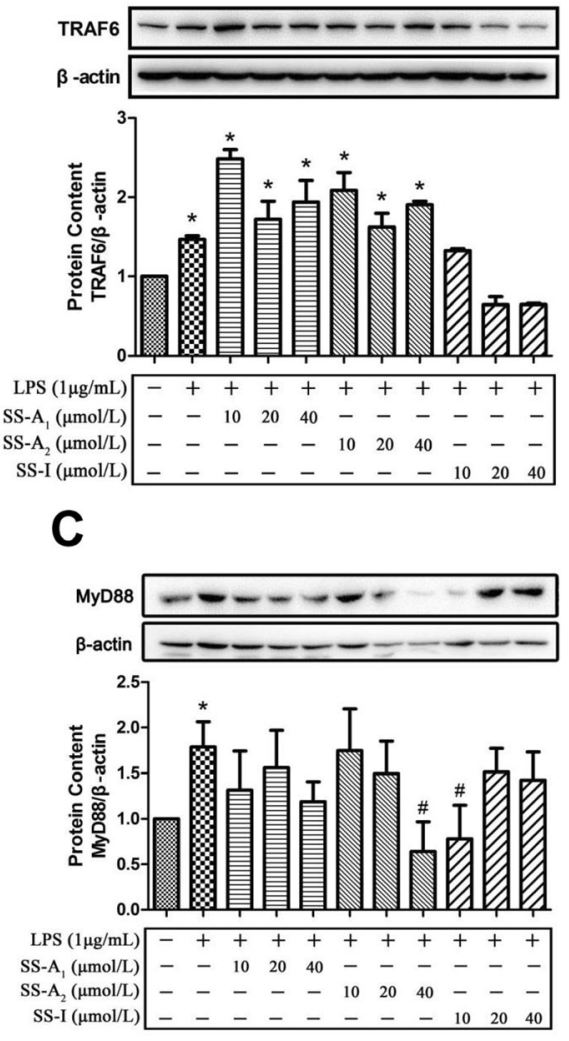

$\mathbf{E}$
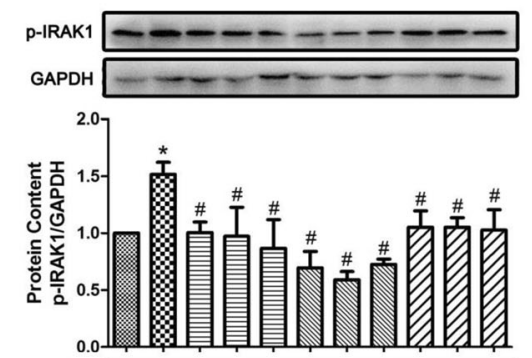

$\operatorname{LPS}(1 \mu \mathrm{g} / \mathrm{mL})-++++++++++$

$\begin{array}{llllllllllll}\text { SS-A }(\mu \mathrm{mol} / \mathrm{L}) & - & - & 10 & 20 & 40 & - & - & - & - & - & - \\ \mathrm{SS}-\mathrm{A}_{2}(\mu \mathrm{mol} / \mathrm{L}) & - & - & - & - & - & 10 & 20 & 40 & - & - & -\end{array}$

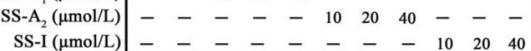

Fig. 4 Effects of soyasaponins on the protein levels of molecules in TLR4/MyD88 signaling pathway in LPS-stimulated RAW264.7 macrophages. RAW264.7 macrophages were pre-treated with graded concentrations $(10,20$ or $40 \mu \mathrm{mol} / \mathrm{L})$ of soyasaponins $\left(A_{1}, A_{2}\right.$, or I) for $2 \mathrm{~h}$ and then stimulated with LPS $(1 \mathrm{\mu g} / \mathrm{mL})$ for $30 \mathrm{~min}(\mathbf{a}$ and $\mathbf{b}), 1 \mathrm{~h}(\mathbf{c})$, or $3 \mathrm{~h}$ (d and $\mathbf{e})$. The levels of molecules (MD-2, TLR4, TIRAP, MyD88, p-IRAK4, p-IRAK1 and TRAF6) in TLR4/MyD88 signaling pathway were measured by western blotting. Results reported are Means \pm SD of three independent experiments. Data were statistically analyzed by using one-way ANOVA of SPSS software. *: $p<0.05$ v.s. control, \#: $p<0.05$ v.S. LPS alone

results show that soyasaponins $\left(A_{1}, A_{2}\right.$, or $\left.I\right)$ can inhibit the expression of MyD88 and TRAF6 in MyD88transfected HEK293T cells.

\section{Discussion}

Previous studies indicate that soyasaponins may reduce inflammation by regulating TLR4/MyD88 signaling pathway. However, the underlying mechanisms are not fully understood. This study made some novel understanding about the regulation of soyasaponins on TLR4/ MyD88-mediated inflammation.

First, results from this study further support the in vivo anti-inflammatory bioactivities of soyasaponins. In recent years, many studies have demonstrated that soyasaponins exhibit anti-inflammatory bioactivities by reducing the pro-inflammatory cytokines and/or mediators (TNFa, IL- 
A

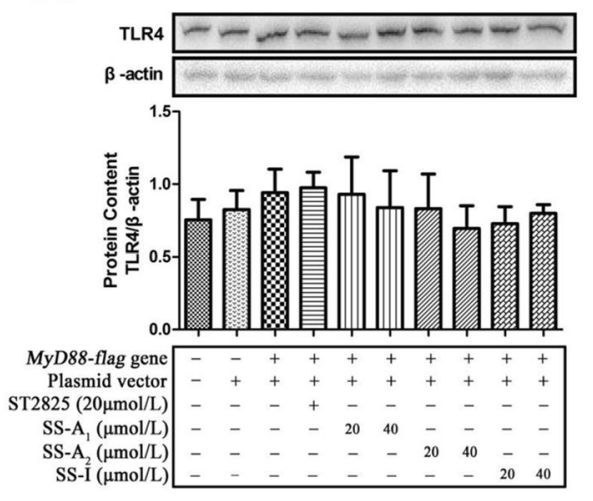

C

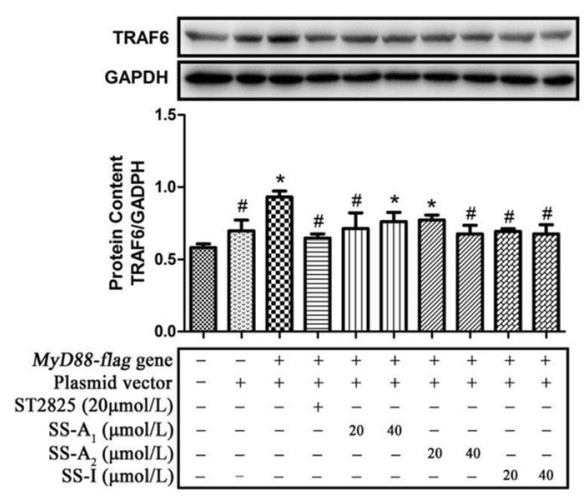

B

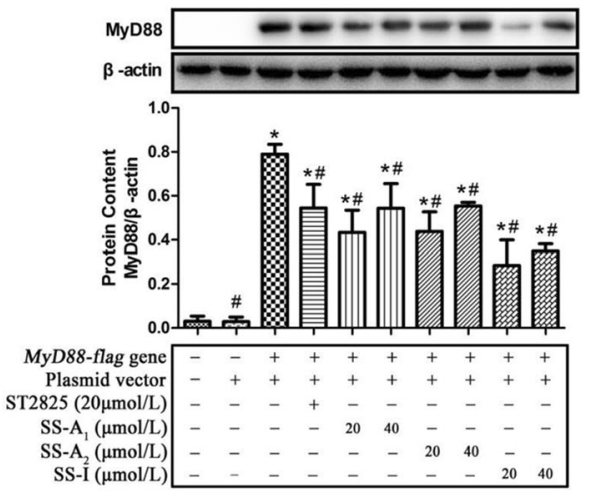

D
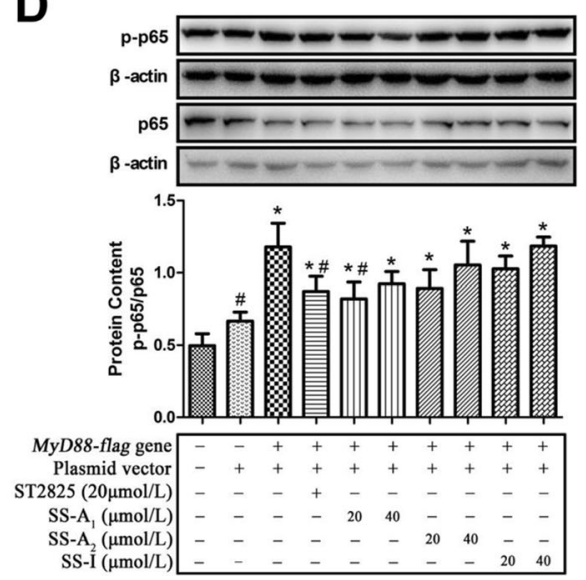

Fig. 5 Soyasaponins inhibit the protein expression of MyD88 and TRAF6, and activation of NF-KB in MyD88-transfected HEK293T cells. HEK293T cells were transfected with MyD88-flag plasmid for $24 \mathrm{~h}$, and then treated with graded concentration (20 or $40 \mu \mathrm{mol} / \mathrm{L})$ of soyasaponin $\left(\mathrm{A}_{1}, \mathrm{~A}_{2}\right.$ or I) or ST2825 (a MyD88 inhibitor) for $6 \mathrm{~h}$. The protein levels of TLR4 (a), MyD88 (b), TRAF6 (c), p-p65 and p65 (d) were measured by western blotting. Results reported are Means \pm SD of three independent experiments. Data were statistically analyzed by using one-way ANOVA of SPSS software. *: $p<0.05$ v.s. control, \#: $p<0.05$ v.s. MyD88-flag plasmid transfected group

$1 \beta$, IL-6, MCP-1, iNOS, NO, COX-2 and $\mathrm{PGE}_{2}$ ) [7-14, 16-19]. However, only a few of investigations provided in vivo evidences. Lee et al. (2010) demonstrated that oral administration of soyasaponin I (10 and $20 \mathrm{mg} / \mathrm{kg}$ ) to TNBS-induced colitic mice significantly reduced inflammatory markers, colon length, myeloperoxidase, lipid peroxide (malondialdehyde and 4-hydroxy-2-nonenal), proinflammatory cytokines and NF- $\mathrm{kB}$ activation in the colon [12]. In 2011, the same lab reported that oral administration of soyasaponin $\mathrm{Ab}(10$ and $20 \mathrm{mg} / \mathrm{kg}$ ) also inhibited colon shortening, myeloperoxidase activity, the expression of COX-2 and iNOS, and activation of NF- $\mathrm{KB}$ in TNBSinduced colitic mice [13]. These two studies showed that soyasaponins (I and $\mathrm{Ab}$ ) can ameliorate colitis indicating their bioactivities to inhibit inflammation in vivo. It is known that the exertion of physiological functions of phytochemicals in vivo is largely dependent on its absorption and bioavailability. Soyasaponins can be metabolized and degraded to its aglycones (soyasapogenols) by gut microbes [29, 33]. However, both soyasaponin I and its aglycone (soyasapogenl B) have limited absorption by Caco-2 intestinal cells and limited bioavailability in women [29]. In rats, chickens and mice after oral administration, neither soyasaponins nor soyasapogenols were found in the urine or blood based on thin-layer chromatography (TLC) and hemolysis assays [33]. Yoshikoshi et al. (1995) also indicated that neither soyasaponins nor its aglycones (soyasapogenols) were detected in the blood or urine of rats fed with a soybean hypocotyl diet [34]. However, more recently, group B soyasaponins (I and V), deacetyl-soyasaponin $\mathrm{A}_{1}$ and soyasapogenols (A and $\mathrm{B}$ ) could be detected in human or rat serum by using highly sensitive analytical method of high-performance liquid chromatography coupled with electrospray ionization tandem mass spectrometry (HPLC-MS/MS) [35, 36]. These studies suggest that oral dosing of soyasaponins and soyasapogenols can be absorbed but its absorption efficiency is low. Therefore, soyasaponins may probably exert anti- 
inflammatory bioactivities in vivo through direct or indirect mechanism or both. The direct mechanism is that soyasaponins may be absorbed into the blood and transported to the targeted organs or tissues to reduce inflammation therein. The indirect mechanism is that soyasaponins may antagonist inflammation through exerting bioactive effects in the intestine (especially in the colon) without absorption. It seems that the in vivo antiinflammatory bioactivities of soyasaponins are to a large extent via the indirect mechanism because the absorption and bioavailability of soysaponins is limited [29]. The two studies from Lee et al. found that soyasaponins exerted anti-inflammatory effects in the colon, which suggests that soyasaponins (or most of them) may go directly into the colon, be metabolized to its aglycones (if not all, at least some of them) and play bioactive roles therein $[12,13]$. We recently showed that oral administration of soysaponins $\left(\mathrm{A}_{1}, \mathrm{~A}_{2}\right.$ or $\left.\mathrm{I}\right)$ reduced both systemic inflammation and local tissue (hepatic and adipose) inflammation in HFD-induced obese mice [7]. In that study, evidences supported the indirect mechanism of in vivo antiinflammatory abilities of soyasaponins, i.e. decreased the lipids accumulation in liver and adipose tissues by promoting its fecal excretion and decreasing intestinal absorption. However, that study did not exclude the possibility that soyasaponins were directly absorbed and transported to the liver and adipose tissues to exert antiinflammatory activities. In the present study, we used an inflammatory model of ICR mice with intravenous injection of LPS via tail vein to investigate the in vivo antiinflammatory bioactivities of soyasaponins. We found that oral administration of soysaponins $\left(\mathrm{A}_{1}, \mathrm{~A}_{2}\right.$ or $\left.\mathrm{I}\right)$ could reduce both systemic inflammation (decreased levels of TNF $\alpha$, IL- 6 and NO in serum) and local inflammation in liver (decreased mRNA expression of TNF $\alpha$, IL-6, IL-1 $\beta$, COX-2 and iNOS in liver tissues). Inflammation induced by intravenous injection of LPS via tail vein means that the gastrointestinal environment is not involved during the development of systemic and liver inflammation. Thus, this study indicates that soyasaponins may be absorbed into the blood, transported to the liver, and exert anti-inflammatory functions therein. Of course, the absolutely direct evidence is to define the absorptive and distributive concentrations of soyasaponins in blood and organs (e.g. liver). However, the quantification of trace amount of soyasaponins in blood and tissues is still challengeable. Such study is currently on the way in our lab. A study from Hong et al. showed that oral administration of soyasaponins $\mathrm{Ab}$ and $\mathrm{Bb}$ prevented scopolamine-induced memory impairment in mice by increasing brain-derived neurotrophic factor (BDNF) expression and cAMP response element-binding (CREB) phosphorylation in the hippocampus [37]. Although this study did not focus on the anti-inflammatory effects of soyasaponins, it still indicated that soyasaponins might be absorbed and transported to the brain and exerted its bioactivities. In 2016, Lin et al. showed that intraperitoneal administration of soyasaponin $\mathrm{Ab}(12.5,25$ and $50 \mathrm{mg} / \mathrm{kg})$ inhibited LPSinduced acute lung injury in mice through attenuating lung pathological changes, edema, the expression of COX2 and iNOS in lung tissues, as well as TNFa, IL-6, IL-1 $\beta$ and $\mathrm{NO}$ production in mice [38]. Furthermore, soyasaponin $\mathrm{Ab}$ activated liver $\mathrm{X}$ receptor alpha (LXRa) which is a member of the nuclear hormone receptor superfamily of ligand-activated transcription factors with antiinflammatory effects. This study suggests that soyasaponins administrated by intraperitoneal injection can probably be distributed to lung and liver and play antiinflammatory functions therein. Collectively, these studies indicate that soyasaponins do have in vivo antiinflammatory bioactivities and our present study's results further support this.

Secondly, the most important finding of this study is that soyasaponins $\left(A_{1}, A_{2}\right.$ or $\left.I\right)$ can downregulate the LPS-increased expression of molecules in TLR4/MyD88 signaling pathway both in vivo and in vitro. LPS is one of the best studied immunostimulatory components of gram-negative bacteria. It has been widely used to establish inflammatory cell and animal models because it can induce both systemic and local tissue (e.g. liver, lung) inflammation $[20,28]$. LPS stimulation can initiate TLR4 signaling by forming a complex with several proteins including TLR4, CD14 and MD-2. Following this, the intracellular MyD88-dependent signals are activated and transduced involving downstream molecules of TIRAP, IRAK-4, IRAK-1 and TRAF6 [20]. In the present study, soyasaponins $\left(A_{1}, A_{2}\right.$ or I) significantly reduced the LPSincreased expression of MD-2, TLR4, MyD88, TIRAP and TRAF6, and phosphorylation of IRAK-4 and IRAK1 in liver tissues of mice, which suggest the regulation of soyasaponins on TLR4/MyD88 signaling in vivo. To date, only one study from Lee et al. (2011) reported the effects of soyasaponins on TLR4/MyD88 signaling in vivo. They found that oral administration of soyasaponin $\mathrm{Ab}(10$ and $20 \mathrm{mg} / \mathrm{kg})$ to TNBS-induced colitic mice inhibited the expression of TLR4 and the phosphorylation of IRAK-1 in colon epithelial cells [13]. This is in accordance with part of our present results. In addition, a plant steroid saponin (Dioscin) with similar chemical structure to soyasaponin, has recently shown to alleviate LPS-induced inflammatory liver injury by decreasing the expressions levels of TLR4, MyD88, IRAK-1and TRAF6 in liver tissues of both mice and rat [28]. In contrast to the lack of investigations in vivo, quite a number of in vitro studies have investigated the molecular mechanisms (including TLR4 signaling) underlying soyasaponin's anti-inflammatory bioactivities. It has been shown that soyasaponins can reduce inflammation by inhibiting 
the PI3K/Akt $[7,17]$, NF- $k B[7,11,12,17]$ and MAPKs $[13,18,19]$ signaling pathway. NF-kB and MAPKs signaling which control the expression of pro-inflammatory cytokines are the downstream targets of TLR4 signaling pathway [20]. In LPS-stimulated mice peritoneal macrophages, soyasaponin Ab not only repressed the TLR4 expression and the IRAK-1 phosphorylation but also inhibited the binding of LPS to TLR4 [13]. Fussbroich et al. (2015) investigated the immune modulatory effect of soyasaponin I on TLR2- and TLR4-induced inflammation by stimulating the human acute myeloid leukemia-derived cell line MUTZ-3 with four different types of stimulators (the gram-negative Escherichia coli, gram-positive Staphylococcus aureus, LPS or peptidoglycans PGN). They found that the anti-inflammatory capacity of soyasaponin I was based on influencing both monocytic TLR2 and TLR4. Furthermore, soyasaponin I inhibited more effectively whole bacteria compared to solely LPS or PGN suggesting the whole bacteria are more sterically inhibited than the appropriate PAMPs by the unspecific binding of soyasaponin I to the outer membrane of MUTZ-3 cells [27]. This study broadens the anti-inflammatory mechanism of soyasaponin by blocking the binding of stimulators/ligands to TLR4 proposed by Lee et al [13]. In the study of Fussbroich et al., soyasaponin I had no effect on the expression of TLR2 and TLR4 in LPS- or PGN-stimulated MUTZ-3 cells [27]. The reason for explaining the lower effect of soyasaponin I on the expression of TLR levels in MUTZ-3 cells is probably that soyasaponin I had only weak regulation on MAPKs signaling which is the predominant regulator of TLR2 and TLR4 expression on these cells $[12,13,27]$. We previously showed that pre-treatment of soyasaponin $\mathrm{Bb}(40 \mu \mathrm{mol} / \mathrm{L})$ did not alter the protein levels of TLR4, MyD88 and TRIF in LPS (for $15 \mathrm{~min}$ )stimulated RAW264.7 macrophages [18]. It is well known that in in vitro inflammatory cell models, the treating concentration and duration of stimulators that

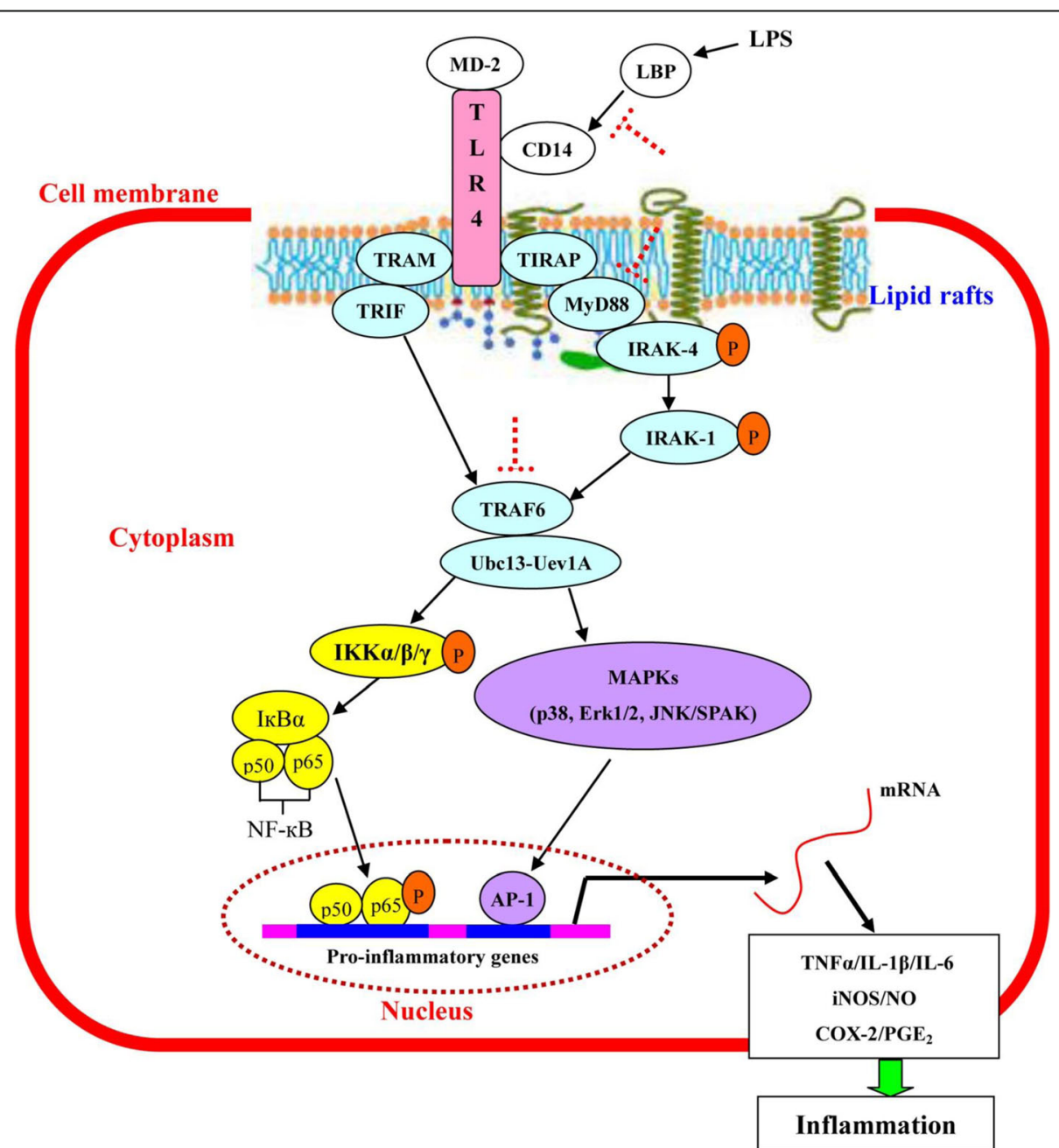

Fig. 6 The schematic diagram of the mechanism of soyasaponins' regulation on TLR4 signaling pathway. The red dotted T-shapes indicate the possible targets by which soyasaponins regulate TLR4 signals 
used are key factors for regulating inflammation and its underlying molecular signaling. In macrophages, highdose of LPS $(>10 \mathrm{ng} / \mathrm{mL})$ is capable of opening up a flood gate of intracellular pathway through TLR4 and its co-receptors and eventually leading to the activation of NF-kB and MAPKs/AP-1 that contributing to the robust induction of pro-inflammatory mediators [39]. In the present study, we used $1 \mu \mathrm{g} / \mathrm{mL}$ of LPS to simulate RAW264.7 macrophages to establish an in vitro inflammatory cell model to further understand the regulation of soyasaponins $\left(\mathrm{A}_{1}, \mathrm{~A}_{2}\right.$ or I) on TLR4/MyD88-mediated inflammation. LPS stimulation for $10 \mathrm{~min}$ to $24 \mathrm{~h}$ did not produce significant change of the protein levels of MD-2, TLR4 and TIRAP. However, the effects of LPS stimulation on the expression of MyD88 and TRAF6, and the phosphorylation of IRAK-4 and IRAK-1 were dependent on the treatment duration. More specifically, LPS stimulation on macrophages for $30 \mathrm{~min}$ did not change the protein levels of MD-2, TLR4, TIRAP, MyD88, p-IRAK4 and p-IRAK1, which was not affected by pretreatment of soyasaponins $\left(\mathrm{A}_{1}, \mathrm{~A}_{2}\right.$ or I). However, LPS stimulation for 30 min significantly increased the level of TRAF6, which could be blunted by soyasaponin I. Furthermore, LPS stimulation (for $1 \mathrm{~h}$ )-increased level of MyD88 was blocked by soyasaponins ( $A_{2}$ or I). LPS stimulation (for $3 \mathrm{~h}$ )-increased phosphorylation of IRAK4 and IRAK1 was blocked by all soyasaponins $\left(A_{1}, A_{2}\right.$ or I). These results showed that soyasaponins can downregulate the expression of molecules in TLR4/MyD88 signaling pathway in inflammatory macrophages. Furthermore, soyasaponins $\left(A_{1}, A_{2}\right.$, or I), similar to ST2825 (the MyD88 inhibitor), significantly reduced the MyD88 plasmid transfection-induced increase of MyD88 expression levels in HEK293T cells which normally express low MyD88. Together, these results suggest that MyD88 is probably the main target by soyasaponins $\left(A_{1}, A_{2}\right.$, or $\left.I\right)$ in macrophages.

The final finding of this study is that soyasaponins $\left(\mathrm{A}_{1}\right.$, $A_{2}$, or I) can inhibit the recruitments of TLR4 and MyD88 into lipid rafts of liver tissue lysates of LPSchallenged inflamed mice. Lipid rafts is essential for the activation of TLR4/MyD88 signaling [30]. We previously found that soyasaponin $\mathrm{Bb}$ could reduce inflammation by inhibiting the recruitments of TLR4 and MyD88 into lipid rafts in murine macrophages in vitro [18]. Other plant-derived saponins with similar chemical structures to soyasaponins (glycyrrhizin and saikosaponin A) were also shown to be capable of suppressing the recruitment of TLR4 into lipid rafts [40-42]. These studies indicate that recruitments of molecules in TLR4 signaling pathway into lipid rafts may be the anti-inflammatory target by saponin compounds. To the best of our knowledge, the present study, for the first time, provides the in vivo evidence to support soyasaponins' abilities to inhibit the recruitments of TLR4 and MyD88 into lipid rafts.

\section{Conclusion}

This study shows that soyasaponins $\left(\mathrm{A}_{1}, \mathrm{~A}_{2}\right.$ or $\left.\mathrm{I}\right)$ can reduce inflammation by downregulating MyD88 expression and suppressing the recruitments of TLR4 and MyD88 into lipid rafts. The present study provides novel understanding about the anti-inflammatory mechanism of soyasaponins. Based on the present study and previous studies from our and other labs, soyasaponins may regulate TLR4 signaling via three kinds of mechanisms: 1) to inhibit the binding of TLR4 to its ligands (e.g. LPS) $[13,27], 2)$ to suppress the recruitment of molecules (TLR4, MyD88 and TRIF) into lipid rafts [18], and 3) to reduce the expression of signal molecules [13] (the schematic diagram is shown in Fig. 6).

\section{Supplementary information}

Supplementary information accompanies this paper at https://doi.org/10. 1186/s12906-020-2864-2

Additional file $\mathbf{1}$ Table S1. The inflammatory markers in serum of LPSchallenged ICR mice. Table S2. Effects of soyasaponins on the mRNA expression of inflammatory markers in the liver tissues of LPS-challenged ICR mice.

Additional file 2 Figure S1. Animal growth and feed intake of LPSchallenged inflammatory mice. Body weight and feed intake were monitored once a week. Body weight and feed intake were calculated during the establishment of LPS-induced inflammatory model in mice (A-B) and the soyasaponin intervention trial (C-D). Results reported are Means \pm SD of $n=15$ (C) and $n=3$ (D) for each group. Data were statistically analyzed by using t-test or one-way ANOVA of SPSS software. Figure S2. The protein levels of molecules in TLR4/MyD88 signaling pathway in murine macrophages stimulated by LPS for different time. The murine RAW264.7 macrophages were treated with $1 \mu \mathrm{g} / \mathrm{mL}$ of LPS for different time (30 min to $24 \mathrm{~h}$ ). The levels of molecules (MD-2, TLR4, MyD88, TIRAP, p-IRAK4, p-IRAK1 and TRAF6) in TLR4/MyD88 signaling pathway were determined by western blotting. Results reported are Means \pm SD of three independent experiments. All data were statistically analyzed by using one-way ANOVA of SPSS software. ${ }^{*}: p<0.05$ v.S. control.

\section{Abbreviations}

Akt: Protein kinase B; BDNF: Brain-derived neurotrophic factor; BW: Body weight; CD14: Cluster of differentiation 14; CD68: Cluster of differentiation 68; COX-2: Cyclooxygenase 2; CREB: CAMP response element-binding; DDMP: 2, 3-dihydro-2, 5-dihydroxy-6-methyl-4H-pyran-4-one; GAPDH: Glyceraldehyde3-phosphate dehydrogenase; HFD: High fat diet; HPLC: High-performance liquid chromatography coupled with electrospray ionization tandem mass spectrometry; HRP: Horseradish peroxidase; ICAM-1: Intercellular cell adhesion molecule-1; ICR mice: Institute of cancer research mice; IKK: Inhibitor of nuclear factor kappa-B kinase; IL-1ß: Interleukin 1 beta; IL-6: Interleukin 6; iNOS: Inducible nitric oxide synthase; IRAK1: Interleukin-1 receptor-associated kinase 1; IRAK4: Interleukin-1 receptor-associated kinase 4; IKB: Inhibitor of nuclear factor kappa-B; IkBa: Nuclear factor of kappa light polypeptide gene enhancer in B-cells inhibitor, alpha; LBP: LPS-binding protein;

LPS: Lipopolysaccharide; LXRa: Liver X receptor alpha; MAPKs: Mitogenactivated protein kinases; MCP-1: Monocyte chemoattractant protein 1.; MD2: Myeloid differentiation protein-2.; MES: 2-(N-morpholino)-ethanesulfonic acid.; MyD88: Myeloid differentiation factor 88.; NCDs: Non-communicable chronic diseases.; NF-kB: Nuclear factor kappa B.; NO: Nitric oxide.;

PAMPs: Pathogen-associated molecular patterns.; PGE $_{2}$ : Prostaglandin $\mathrm{E}_{2}$ :; PI3K: Phosphoinositide 3-kinase.; PMSF: Phenylmethylsulfonyl fluoride.; PVDF: Polyvinylidene fluoride.; RIPA: Radio-Immunoprecipitation Assay.; TAK1: Transforming growth factor- $\beta$-activated kinase 1.; TIRAP: Tollinterleukin 1 receptor domain containing adaptor protein.; TLC: Thin-layer chromatography.; TLR4: Toll-like receptor 4.; TNBS: 3, 4, 5-

trinitrobenzenosulfonic acid.; TNFa: Tumor necrosis factor alpha.; TRAF6: TNF 
receptor associated factor 6.; TRIF: Toll/interleukin 1 receptor domaincontaining adaptor inducing IFN- $\beta_{\text {.; }}$ Ubc13: Ubiquitin-conjugating enzyme 13.; Uev1A: Ubiquitin-conjugating enzyme $E_{2}$ variant 1 isoform $A$.; WHO: World Health Organization.

\section{Acknowledgements}

Not applicable.

\section{Authors' contributions}

LZ and QL were responsible for the study concept and design; JC cultured the cells and did the experiment of lipid rafts and cell transfection. HU and ZZ performed the animal experiments (feeding, growth monitoring, LPS challenge and soyasaponins intervention); XG conducted the western blotting; CS and LX did the FQ-PCR; XW and FX performed the ELISA analysis of inflammatory markers; JC, ZZ, and LZ carried out the statistical analysis and interpretation of data; JC, QL and LZ wrote the manuscript; All authors read and approved the final manuscript.

\section{Funding}

This work was supported by grants from National Natural Science Foundation of China (NSFC) (No.81573125, No. 81872621 and No.81102130, to Prof. Longying Zha) in the design of study and collection, analysis, and interpretation of data and in writing the manuscript, the Natural Science Foundation of Guangdong Province, China (No. 2014A030313313, to Prof. Longying Zha) in the collection of data, the Research Start-up Plan of Southern Medical University (No.CX2016N012, to Prof. Longying Zha) in the analysis and interpretation of data, and the Scientific Enlightenment Plan of Southern Medical University (No. B219339024, to Prof. Longying Zha and Yuanhao Wei) in the collection of data.

\section{Availability of data and materials}

Materials used and data collected in this study are available from the corresponding author on reasonable request.

\section{Ethics approval and consent to participate}

This study was approved by the Southern Medical University Experimental Animal Ethics Committee (allowance number: SMUA2016013). All procedures involving animals and their care followed the guidelines for the standard care of animals from the Institutional Animal Care and Use Committee of Southern Medical University.

\section{Consent for publication}

All co-authors have consented for the publication of this manuscript.

\section{Competing interests}

The authors declare that they have no competing interests.

Received: 26 November 2019 Accepted: 21 February 2020 Published online: 03 June 2020

\section{References}

1. World Health Organization, Noncommunicable diseases and their risk factors, https://www.who.int/ncds/en/..

2. Grivennikov SI, Greten FR, Karin M. Immunity, inflammation, and cancer. Cell. 2010;140:883.

3. Meester FD, Wilczynska A, Singh RB, Wilson DW, Hungin AS, Pella D, Fedacko J, Siegelova J, Fiser B, Galli C, Cornélissen G, Halberg F. Tissue inflammation and NCDs: dietary control, physical exercise and mind body interactions. BMC Proc. 2012:6(Suppl 3):53.

4. Gislason GH, Rasmussen JN, Abildstrom SZ, Schramm TK, Hansen ML, Fosbol EL, Sorensen R, Folke F, Buch P, Gadsboll N, Rasmussen S, Poulsen HE, Kober L, Madsen M, Torp-Pedersen C. Increased mortality and cardiovascular morbidity associated with use of nonsteroidal anti-inflammatory drugs in chronic heart failure. Arch Intern Med. 2009;169:141-9.

5. Zhang Y, Gan R, Li S, Zhou Y, Li A, Xu D, Li H. Antioxidant phytochemicals for the prevention and treatment of chronic diseases. Molecules. 2015; 20(12):21138-56

6. Belobrajdic DP, Bird AR. The potential role of phytochemicals in wholegrain cereals for the prevention of type-2 diabetes. Nutr J. 2013;12:62.

7. Xie Q, Gu X, Chen J, Liu M, Xiong F, Wu X, Zhang Y, Chen F, Chen H, Li M, Sun S, Chu X, Zha L. Soyasaponins reduce inflammation and improve serum lipid profiles and glucose homeostasis in high fat diet-induced obese mice. Mol Nutr Food Res. 2018:62:e1800205.

8. Gurfinkel DM, Rao AV. Soyasaponins: the relationship between chemical structure and colon anticarcinogenic activity. Nutr Cancer. 2003:47:24.

9. Guang C, Chen J, Sang S, Cheng S. Biological functionality of soyasaponins and soyasapogenols. J Agric Food Chem. 2014:62:8247-55.

10. Kang J, Sung M, Kawada T, Yoo H, Kim Y, Kim J, Yu R. Soybean saponins suppress the release of proinflammatory mediators by LPS-stimulated peritoneal macrophages. Cancer Lett. 2005;230:219-27.

11. Zha L, Mao L, Lu X, Deng H, Ye J, Chu X, Sun S, Luo H. Anti-inflammatory effect of soyasaponins through suppressing nitric oxide production in LPSstimulated RAW 264.7 cells by attenuation of NF-kB-mediated nitric oxide synthase expression. Bioorg Med Chem Lett. 2011;21:2415-8.

12. Lee I, Park Y, Yeo H, Han MJ, Kim D. Soyasaponin I attenuates TNBS-induced colitis in mice by inhibiting NF-KB pathway. J Agric Food Chem. 2010;58: 10929-34.

13. Lee I, Park Y, Joh E, Kim D. Soyasaponin Ab ameliorates colitis by inhibiting the binding of lipopolysaccharide (LPS) to toll-like receptor (TLR) 4 on macrophages. J Agric Food Chem. 2011;59:13165-72.

14. Ahn K, Kim J, Oh S, Min B, Kinjo J, Lee H. Effects of oleanane-type triterpenoids from fabaceous plants on the expression of ICAM-1. Biol Pham Bull. 2002;25:1105-7.

15. Oh S, Kinjo J, Shii Y, Ikeda T, Nohara T, Ahn K, Kim J, Lee H. Effects of triterpenoids from Pueraria lobata on immunohemolysis: $\beta$-D-glucuronic acid plays an active role in anticomplementary activity in vitro. Planta Med. 2000;66:506-10.

16. Lan X, Deng K, Zhao J, Chen Y, Xin X, Liu Y, Khan IA, Yang S, Wang T, Wu Q. New triterpenoid saponins from green vegetable soya beans and their antiinflammatory activities. J Agric Food Chem. 2017;65:11065-72.

17. Zha L, Chen J, Sun S, Mao L, Chu X, Deng H, Cai J, Li X, Liu Z, Cao W. Soyasaponins can blunt inflammation by inhibiting the reactive oxygen speciesmediated activation of PI3K/Akt/NF-kB pathway. PLoS One. 2014;9:e107655.

18. Zhang Y, Chen F, Chen J, Huang S, Chen J, Huang J, Li N, Sun S, Chu X, Zha L. Soyasaponin bb inhibits the recruitment of toll-like receptor 4 (TLR4) into lipid rafts and its signaling pathway by suppressing the nicotinamide adenine dinucleotide phosphate (NADPH) oxidase-dependent generation of reactive oxygen species. Mol Nutr Food Res. 2016;60:1532.

19. Yang SH, Le B, Androutsopoulos VP, Tsukamoto C, Shin TS, Tsatsakis AM, Chung G. Anti-inflammatory effects of soyasapogenol I-alphaa via downregulation of the MAPK signaling pathway in LPS-induced RAW 264.7 macrophages. Food Chem Toxicol. 2018;113:211.

20. Lu Y, Yeh W, Ohashi PS. LPS/TLR4 signal transduction pathway. Cytokine. 2008:42:145-51.

21. Chen $C Y$, Kao CL, Liu CM. The cancer prevention, anti-inflammatory and anti-oxidation of bioactive phytochemicals targeting the TLR4 signaling pathway. Int J Mol Sci. 2018;19:2729.

22. Wang Y, Qian Y, Fang Q, Zhong P, Li W, Wang L, Fu W, Zhang Y, Xu Z, Li X, Liang $G$. Saturated palmitic acid induces myocardial inflammatory injuries through direct binding to TLR4 accessory protein MD2. Nat Commun. 2017; 8:13997.

23. Bryant CE, Symmons M, Gay NJ. Toll-like receptor signaling through macromolecular protein complexes. Mol Immunol. 2015;63:162.

24. Lye E, Mirtsos C, Suzuki N, Yeh WC. The role of interleukin 1 receptorassociated kinase-4 (IRAK-4) kinase activity in IRAK-4-mediated signaling. J Biol Chem. 2004;279:40653-8.

25. Gohda J, Matsumura T, Inoue J. Cutting edge: TNFR-associated factor (TRAF) 6 is essential for MyD88-dependent pathway but not toll/IL-1 receptor domain-containing adaptor-inducing IFN-beta (TRIF)-dependent pathway in TLR signaling. J Immunol. 2004;173:2913-7.

26. Chang L, Karin M. Mammalian MAP kinase signaling cascades. Nature. 2001; 410:37-40.

27. Fussbroich D, Schubert $R$, Schneider $P$, Zielen S, Beermann C. Impact of soyasaponin I on TLR2 and TLR4 induced inflammation in the MUTZ-3-cell model. Food Funct. 2015;6:1001-10.

28. Yao H, Hu C, Yin L, Tao X, Xu L, Qi Y, Han X, Xu Y, Zhao Y, Wang C, Peng J. Dioscin reduces lipopolysaccharide-induced inflammatory liver injury via regulating TLR4/MyD88 signal pathway. Int Immunopharmacol. 2016;36: $132-41$.

29. Hu J, Reddy MB, Hendrich S, Murphy PA. Soyasaponin I and sapongenol B have limited absorption by Caco-2 intestinal cells and limited bioavailability in women. J Nutr. 2004;134:1867-73. 
30. Xia X, Fu J, Song X, Shi Q, Su C, Song E, Song Y. Neohesperidin dihydrochalcone down-regulates MyD88-dependent and -independent signaling by inhibiting endotoxin-induced trafficking of TLR4 to lipid rafts. Free Radic Biol Med. 2015:89:522.

31. Plociennikowska A, Hromada-Judycka A, Borzecka K, Kwiatkowska K. Cooperation of TLR4 and raft proteins in LPS-induced pro-inflammatory signaling. Cell Mol Life Sci. 2015;72:557.

32. Kitagawa Y, Yamaguchi M, Zhou M, Nishio M, Itoh M, Gotoh B. Human parainfluenza virus type $2 \mathrm{~V}$ protein inhibits TRAF6-mediated ubiquitination of IRF7 to prevent TLR7- and TLR9-dependent interferon induction. J Virol. 2013:87(14):7966-76

33. Gestetner B, Birk Y, Tencer Y. Soybean saponins, fate of ingested soybean saponins and the physiological aspect of their hemolytic activity. J Agric Food Chem. 1968;16:1031-5.

34. Yoshikoshi M, Kahara T, Yoshiki Y, Ito M, Furukawa Y, Okubo K, Amarowicz R. Metabolism and nonabsorption of soybean hypocotyl saponins in the rat model. Acta Aliment. 1995;24:355-64.

35. Jin $M$, Yang $Y$, Su B, Ren Q. Determination of soyasaponins Ba and bb in human serum by high-performance liquid chromatography coupled with electrospray ionization tandem mass spectrometry. J Chromatogr B. 2007; 846:169-75.

36. Shuichi K, Shunsuke S, Toshiro S. Comparison of bioavailability (I) between soyasaponins and soyasapogenols, and (II) between group A and B soyasaponins. Nutrition. 2014;30:596-601.

37. Hong SW, Yoo DH, Woo JY, Jeong JJ, Yang J, Kim DH. Soysaponins Ab and bb prevent scopolamine-induced memory impairment in mice without the inhibition of acetylcholinesterase. J Agric Food Chem. 2014;62:2062-8.

38. Lin J, Cheng Y, Wang T, Tang L, Sun Y, Lu X, Yu H. Soyasaponin Ab inhibits lipopolysaccharide-induced acute lung injury in mice. Int Immunopharmacol. 2016;30:121-8.

39. Maitra U, Deng H, Glaros T, Baker B, Capelluto DGS, Li Z, Li L. Molecular mechanisms responsible for the selective and low-grade induction of proinflammatory mediators in murine macrophages by lipopolysaccharide. J Immunol. 2012;189:1014-23.

40. Wei Z, Wang J, Shi M, Liu W, Yang Z, Fu Y. Saikosaponin a inhibits LPS induced inflammatory response by inducing liver $X$ receptor alpha activation in primary mouse macrophages. Oncotarget. 2016;7:48995.

41. Fu Y, Zhou E, Wei Z, Song X, Liu Z, Wang T, Wang W, Zhang N, Liu G, Yang Z. Glycyrrhizin inhibits lipopolysaccharide-induced inflammatory response by reducing TLR4 recruitment into lipid rafts in RAW264.7 cells. Biochim Biophys Acta. 2014;1840:1755.

42. Fu Y, Hu X, Cao Y, Zhang Z, Zhang N. Saikosaponin a inhibits lipopolysaccharide-oxidative stress and inflammation in human umbilical vein endothelial cells via preventing TLR4 translocation into lipid rafts. Free Radic Biol Med. 2015;89:777-85

\section{Publisher's Note}

Springer Nature remains neutral with regard to jurisdictional claims in published maps and institutional affiliations.

Ready to submit your research? Choose BMC and benefit from:

- fast, convenient online submission

- thorough peer review by experienced researchers in your field

- rapid publication on acceptance

- support for research data, including large and complex data types

- gold Open Access which fosters wider collaboration and increased citations

- maximum visibility for your research: over $100 \mathrm{M}$ website views per year

At $\mathrm{BMC}$, research is always in progress.

Learn more biomedcentral.com/submissions 